\title{
Evaluation on the Lightning Breakdown Voltages of Palm Oil and Coconut Oil under Non-Uniform Field at Small Gap Distances
}

\author{
Yee Von Thien*, Norhafiz Azis ${ }^{\dagger}$, Jasronita Jasni*, Mohd Zainal Abidin Ab Kadir*, \\ Robiah Yunus**, Mohd Taufiq Ishak*** and Zaini Yaakub ${ }^{\S}$
}

\begin{abstract}
In recent years, there are a number of studies that have been carried out to explore the alternative for Mineral Oil (MO) as dielectric insulating fluid in transformers due to the increasing tight regulation on safety and environment. Vegetable oils have been identified as suitable candidate since it is biodegradable, non-toxic and high flash/fire points which ensure more in-service safety. Among the types of vegetable oils considered for transformers application are Palm Oil (PO) and Coconut Oil (CO). This paper presents an experimental study on the lightning breakdown voltages of PO and CO under non-uniform electric field based on needle-sphere electrodes configuration at 3 small gap distances. The type of PO used in this study is Refined Bleached and Deodorized Palm Oil (RBDPO) Olein. The main focus of this study is to examine the lightning breakdown performance of RBDPO and CO under different test conditions and assess its suitability as dielectric insulating fluid in transformers. The effect of voltage polarities (positive and negative) and testing methods (risingvoltage, up-and-down and multiple-voltage) were investigated. The data obtained from all tests were analysed by Weibull distribution in order to determine the withstand voltages for each type of oils. It was found that the breakdown voltages of RBDPO and $\mathrm{CO}$ are comparable with $\mathrm{MO}$ under positive lightning impulse. Under negative lightning impulse, the breakdown voltage of MO is slightly higher than RBDPO and CO. There is no significant effect of testing methods and voltage polarities on lightning breakdown voltages of RBDPO and CO. Based on the statistical analysis, it is found that the breakdown voltages of RBDPO and $\mathrm{CO}$ at $1 \%$ probability are slightly lower than MO.
\end{abstract}

Keywords: Palm oil, Coconut oil, Lightning breakdown voltage, Non-uniform field, Transformers

\section{Introduction}

Among the types of vegetable oils considered for potential application as dielectric insulating fluid in transformers are Palm Oil (PO) and Coconut Oil (CO). In general, there are different types of PO that can be extracted from the palm nut such as Crude Palm Oil (CPO), Refined, Bleached and Deodorized Palm Oil (RBDPO) and Palm Kernel Oil (PKO) [1]. RBDPO Olein can be obtained through the fractionation process from RBDPO. RBDPO is the most common fluid considered for transformers application. On the other hand, $\mathrm{CO}$ can be extracted from the kernel of a matured coconut from a coconut palm. Previous studies on RBDPO and CO covered on different aspects including AC / lightning breakdown voltages, partial discharge, dielectric, physical and chemical properties [2-14].

$\dagger \quad$ Corresponding Author: Centre for Electromagnetic and Lightning Protection Research (CELP), Universiti Putra Malaysia, 43400 UPM Serdang, Malaysia. (norhafiz@upm.edu.my)

* Centre for Electromagnetic and Lightning Protection Research (CELP), Universiti Putra Malaysia, 43400 UPM Serdang, Malaysia.

** Dept. of Chemical and Environmental Engineering, Universiti Putra Malaysia, 43400 UPM Serdang, Malaysia.

*** Dept. of Electrical and Electronic Engineering, Universiti Pertahanan Nasional Malaysia, 57000 UPNM Sungai Besi, Malaysia.

$\S \quad$ Hyrax Oil Sdn. Bhd, Malaysia.

Received: January 19, 2015; Accepted: October 6, 2015
Currently, there are still less studies that have been carried out to examine the lightning breakdown performances and mechanisms of RBDPO and CO under non-uniform fields with consideration on different testing conditions. Considering the future application of these oils in high voltage transformers, it is therefore essential to examine the lightning breakdown properties of these oils since the knowledge can be important for transformers insulation design.

Previously, there were a number of lightning studies that had been carried out on other types of vegetable oils such as natural and synthetic esters [15-27]. Among the common lightning study is the performance under non-uniform field. Non-uniform field study is normally carried out to represent an event when discharge is initiated by some defects in a transformer. It can be set up by point-plane or point-sphere configurations which can simulate the imperfections that could occur in transformers [28]. There are several parameters that can affect the breakdown strengths and mechanisms of dielectric insulating fluids under non-uniform field such as the composition of fluids, polarity/magnitude of electrical fields and the geometry of electrodes [29].

Several lightning studies under non-uniform field showed that the $50 \%$ breakdown voltages of esters under 
negative polarity were much higher than positive polarity [16-19]. In one of the study, the lightning breakdown voltages of esters under negative polarity were $63 \%$ higher than under positive polarity at gap distance of $50 \mathrm{~mm}$ [16]. Other study at gap distance of $100 \mathrm{~mm}$ also showed the same pattern [17]. However, at small gap distances between $5 \mathrm{~mm}$ and $20 \mathrm{~mm}$, it was found that the $50 \%$ breakdown voltages of vegetable oils at negative and positive polarities were quite close [20].

The lightning breakdown performance of vegetable oils under non-uniform field is also comparable with Mineral Oil (MO). In one of the study, it was reported that at gap distances between $5 \mathrm{~mm}$ and $20 \mathrm{~mm}$, the $50 \%$ breakdown voltages of esters were quite close to Mineral Oil (MO) under both negative and positive polarities [20]. Other studies showed that the $50 \%$ breakdown voltages of vegetable oils were slightly lower than MO at gap distances between $60 \mathrm{~mm}$ and $100 \mathrm{~mm}$ [21-23]. However, as the gap distance increased larger than $100 \mathrm{~mm}$, the $50 \%$ breakdown voltages of vegetable oils were much lower than MO [19, 21-23]. In one of the study, under very large gap distance, i.e. $1000 \mathrm{~mm}$, the $50 \%$ breakdown voltages of natural ester could be $40 \%$ lower than MO [19].

In this paper, the lightning breakdown voltages of RBDPO and CO under non-uniform field at small gap distances are examined. The influences of voltage polarities and testing methods on the breakdown voltages RBDPO and CO at different gap distances are investigated. Next, the withstand voltages of RBDPO and CO are determined based on Weibull distribution and compared with MO. The main aim of this work is to evaluate the performance of lightning breakdown voltages of RBDPO and $\mathrm{CO}$ as compared to $\mathrm{MO}$ under non-uniform field with consideration on different voltage polarities and testing methods at small gap distances.

\section{Experimental Description}

\subsection{Fluids under test and pre-processing procedure}

Three samples of RBDPO Olein and one sample of each $\mathrm{CO}$ and MO were used in this study. Both RBDPO and $\mathrm{CO}$ were obtained from readily available cooking oil products in the market. Table 1 shows the characteristics of both RBDPO and CO samples. All RBDPO samples have almost the same composition of saturated, polyunsaturated

Table 1. Fat, vitamin E/A contents of all samples

\begin{tabular}{c|c|c|c|c|c}
\hline Samples & $\begin{array}{c}\text { S. fat } \\
(\mathrm{g})\end{array}$ & $\begin{array}{c}\text { P-U.S. fat } \\
(\mathrm{g})\end{array}$ & $\begin{array}{c}\text { M-U.S. fat } \\
(\mathrm{g})\end{array}$ & $\begin{array}{c}\text { V. E } \\
(\mathrm{mg})\end{array}$ & $\begin{array}{c}\text { V. A } \\
(\mu \mathrm{g})\end{array}$ \\
\hline RBDPOA & 44.4 & 12.2 & 43.3 & 50.0 & - \\
\hline RBDPOB & 43.0 & 14.0 & 43.0 & 75.0 & - \\
\hline RBDPOC & 45.4 & 11.6 & 43.0 & 4.4 & 264 \\
\hline CO & 92.8 & 3.6 & 3.6 & - & - \\
\hline
\end{tabular}

* S. fat $=$ Saturated fat, P-U.S. fat $=$ Polyunsaturated fat, M-U.S.

fat $=$ Monounsaturated fat, V. E= Vitamin E, V. A= Vitamin A and monounsaturated fats. The main difference is on the composition of vitamin A and vitamin E. RBDPOB has the highest vitamin $\mathrm{E}$ while only RBDPOC has vitamin A and the lowest content of vitamin E. On the other hand, CO mainly consists of saturated fat and does not contain both of vitamin A and vitamin E.

All samples were first pre-processed by filtering 3 times through a membrane filter with a pore size of $0.2 \mu \mathrm{m}$. Next, all samples were dried for 48 hours in an oven at $85^{\circ} \mathrm{C}$. All samples were rested at ambient temperature for another 24 hours before tested for lightning breakdown voltage.

\subsection{Test setup}

The lightning breakdown voltage test was carried out based on needle-sphere electrodes configuration as shown in Fig. 1. A cylindrical test cell was made from transparent Perspex with a volume of $300 \mathrm{ml}$ according to IEC 60897 [30]. Both needle and sphere electrodes were made from copper. The radius of the needle tip is $200 \mu \mathrm{m}$ and the diameter of the ground sphere is $12.7 \mathrm{~mm}$. A standard lightning impulse $1.2 / 50 \mu$ s voltage was applied using a TERCO impulse generator. All tests were performed at 2 $\mathrm{mm}, 3.8 \mathrm{~mm}$ and $6 \mathrm{~mm}$ electrodes gap distances under both positive and negative voltage polarities. In order to protect samples and electrodes during tests, a $2.4 \mathrm{k} \Omega$ current limit resistor was added in the circuit in order to limit the breakdown current.

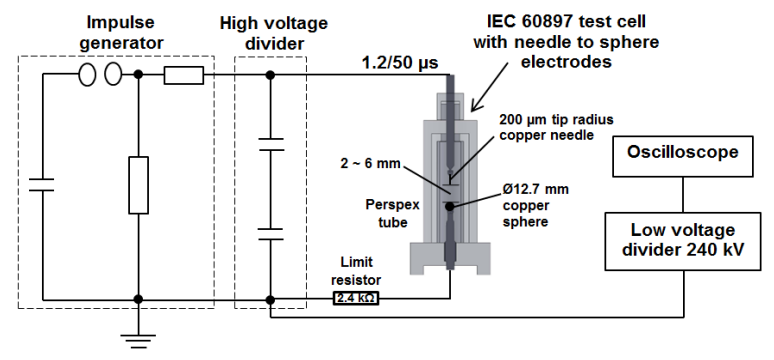

Fig. 1. Test configuration for the lightning impulse

\subsection{Testing methods}

\subsubsection{Rising-voltage method}

Rising-voltage method can be used for testing different types of voltage including both impulse and AC [31,32]. According to this method, for one set of testing, the applied voltage is increased at a constant rate from a specified initial voltage level until the breakdown occurs. Next, the applied voltage is reduced and the previous procedure is repeated. In this study, the initial voltage level was set between $40 \mathrm{kV}$ and $50 \mathrm{kV}$ with a step voltage increment between $2 \mathrm{kV}$ and $5 \mathrm{kV}$. A standing time interval, $\Delta \mathrm{T}$ of 60 seconds was given between each breakdown before the previous procedure is repeated at 1 shot per step increasing rate. In total, 15 breakdowns for each sample were recorded. 


\subsubsection{Up-and-down method}

The up-and-down method was proposed by Dixon and Mood where it is based on an estimation of normally distributed $50 \%$ breakdown voltages [31, 32]. The voltage is initially raises in steps at fixed amplitude of $\Delta U$ from a specified initial voltage at which certainty no breakdown would occurs. Once the first breakdown occurs, the voltage is reduced at the same step of $\Delta \mathrm{U}$ until no breakdown would occur and raised again until the next breakdown occurs. The process is repeated until a specified number of breakdowns are obtained $[31,32]$. The $50 \%$ breakdown voltage provides a prior estimate of the mean [32]. In this study, the initial voltage levels were set between $40 \mathrm{kV}$ and $50 \mathrm{kV}$ and the step voltages were set between $2 \mathrm{kV}$ and 5 $\mathrm{kV}$. The standing time interval, $\Delta \mathrm{T}$ between each breakdown was set to 60 seconds and a total of 30 shots were applied for each sample.

\subsubsection{Multiple-level method}

Multiple-level method is also known as constant voltage method where it is normally used to determine the breakdown probability [32]. At various voltage levels, a fixed number of shots are applied and the number of breakdowns at each voltage level is recorded. Based on the results, a cumulative frequency plot is carried out and the breakdown voltage can be determined. In the present test, 20 shots were applied at each voltage level with a standing time interval, $\Delta \mathrm{T}$ of 60 seconds. The step voltage, $\Delta \mathrm{U}$ between 2 consecutive voltage levels was set to $5 \mathrm{kV}$. According to previous experiences, the initial voltage levels for all samples were set at $35 \mathrm{kV}, 45 \mathrm{kV}$ and $50 \mathrm{kV}$ at gap distances of $2.0 \mathrm{~mm}, 3.8 \mathrm{~mm}$ and $6.0 \mathrm{~mm}$ respectively.

\section{Experimental Results}

\subsection{Influence of voltage polarities on the lightning breakdown voltages at different gap distances}

In this section, the study is carried out based on risingvoltage method. There is only a small influence of voltage polarities on the breakdown voltages of all samples at all gap distances where the highest percentage of difference is only $11 \%$ as shown in Fig. 2. MO has the highest $50 \%$ breakdown voltages at both polarities with values between $48.9 \mathrm{kV}$ and $80 \mathrm{kV}$. Under positive polarity, the $50 \%$ breakdown voltages of RBDPO and CO are comparable with $\mathrm{MO}$ where the highest percentage of difference is less than $11 \%$. Under negative polarity, the $50 \%$ breakdown voltages of RBDPO and $\mathrm{CO}$ are lower than $\mathrm{MO}$ where the highest percentage of difference can be up to $22.5 \%$. Among the RBDPO samples, RBDPOB has the highest $50 \%$ breakdown voltages except at the gap distance of 3.8

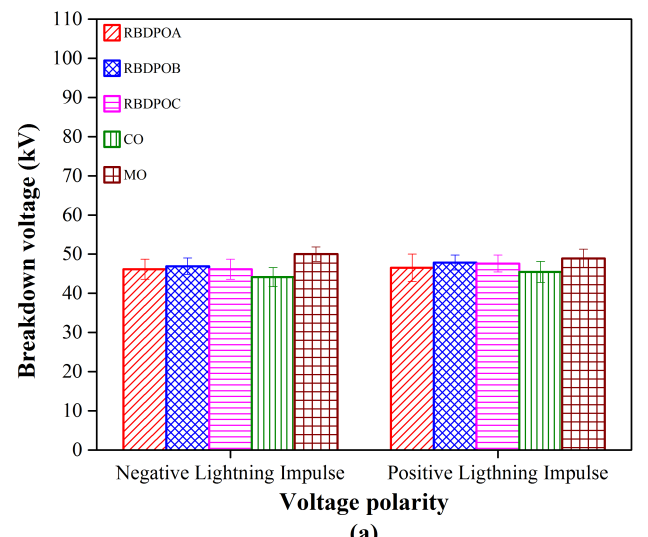

(a)

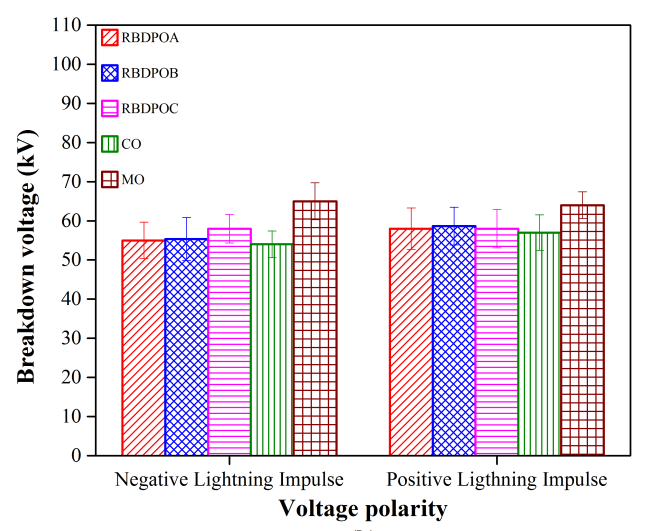

(b)

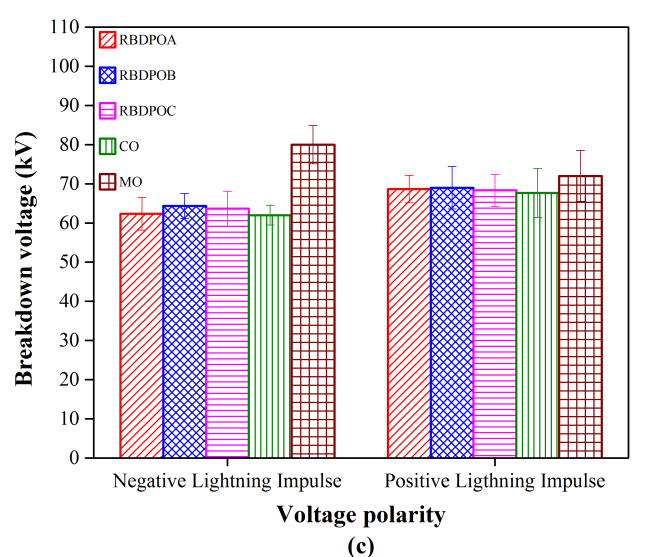

Fig. 2. Influence of voltage polarities on the $50 \%$ breakdown voltages of all samples at gap distances of (a) $2.0 \mathrm{~mm}$; (b) $3.8 \mathrm{~mm}$ and (c) $6.0 \mathrm{~mm}$

$\mathrm{mm}$ and under negative polarity. On the other hand, $\mathrm{CO}$ has the lowest $50 \%$ breakdown voltages at all gap distances under both polarities with values between $43 \mathrm{kV}$ and $69 \mathrm{kV}$.

\subsection{Influence of testing methods on the lightning breakdown voltages at different gap distances}

In this part, the study is carried out under negative voltage polarity. There is only a small effect of testing methods on the breakdown voltages of all samples at all 
gap distances where the highest percentage of difference is $13.8 \%$ as seen in Fig. 3. Multiple-level method has the highest $50 \%$ breakdown voltages compared with the other methods. For all testing methods, MO has the highest 50\% breakdown voltages followed by RBDPO and CO. At gap distance of $2.0 \mathrm{~mm}$, the breakdown voltages of RBDPO and $\mathrm{CO}$ are slightly lower than $\mathrm{MO}$ where the highest percentage of difference is less than $16 \%$ for all testing methods. However, as the gap distances increases to 3.8 $\mathrm{mm}$ and $6.0 \mathrm{~mm}$, the differences of breakdown voltages between $\mathrm{RBDPO} / \mathrm{CO}$ and $\mathrm{MO}$ also increase where the highest percentage of difference can be up to $26.8 \%$.

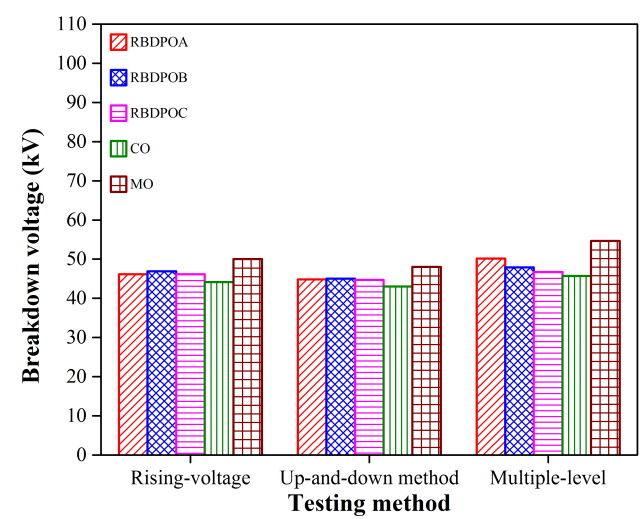

(a)

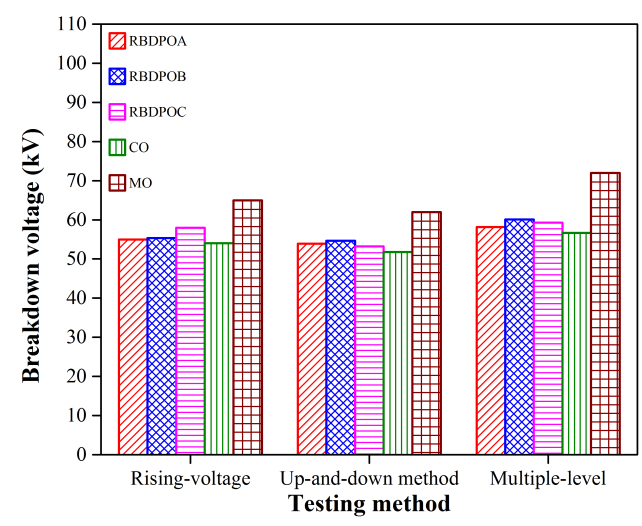

(b)

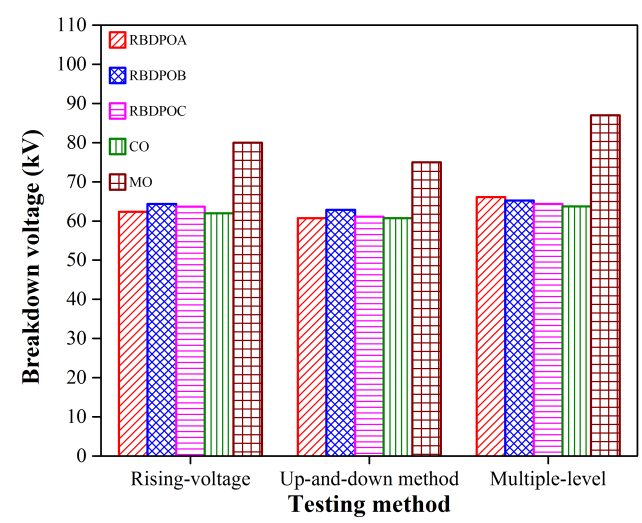

(c)

Fig. 3. Comparison of $50 \%$ breakdown voltages of all samples using various testing methods at gap distances of (a) $2.0 \mathrm{~mm}$; (b) $3.8 \mathrm{~mm}$ and (c) $6.0 \mathrm{~mm}$

\subsection{Determination of lightning withstand voltages}

The lightning withstand voltages can be determined through Weibull distribution where the cumulative distribution function is given in Eq. (1).

$$
F(x)=1-e^{-\left(\frac{x}{\beta}\right)^{\alpha}}
$$

Where $\alpha$ and $\beta$ are shape and scale parameters while $x$ is the measured breakdown data. All breakdown voltage data for different testing methods were compiled according to gap distances and voltage polarities. Next, the numbers of breakdown events at each voltage level were counted and the cumulative probabilities were determined. The data were then fitted by cumulative probability Weibull distribution function given in Eq. (1) and the shape and scale parameter were obtained. The Weibull fittings for each voltage polarities at difference gap distances can be seen in Fig. 4 and Fig. 5. Using the shape and scale

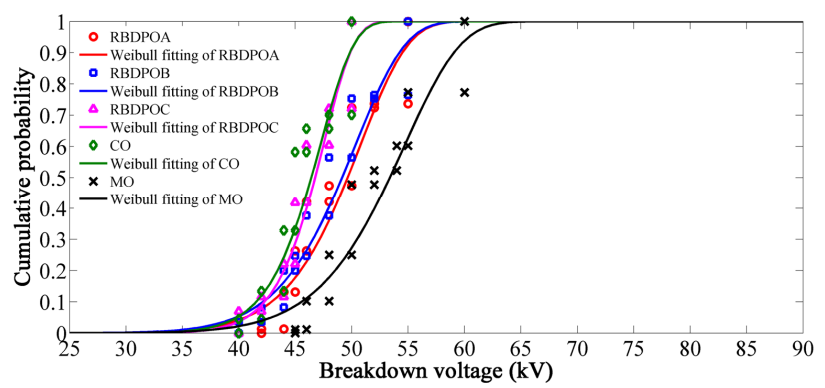

(a)

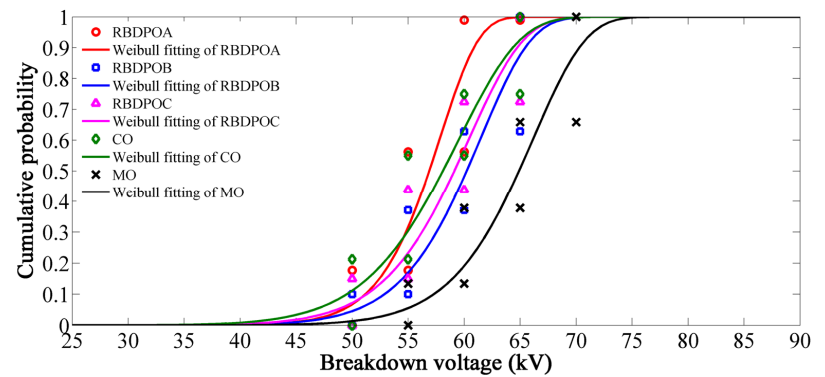

(b)

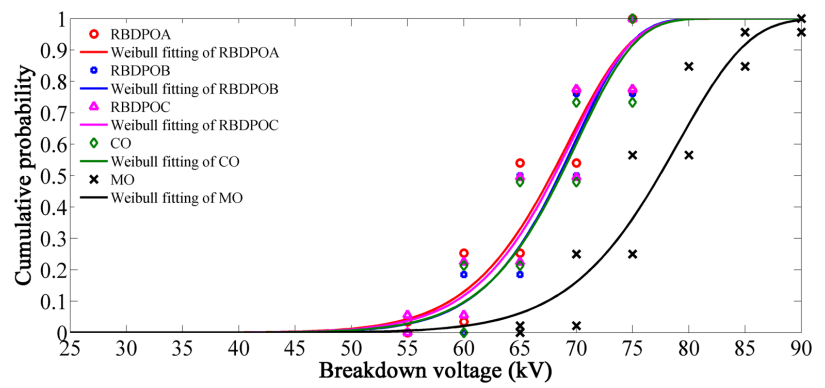

(c)

Fig. 4. Weibull cumulative probability fittings for negative polarity of all samples at gap distances of (a) $2.0 \mathrm{~mm}$; (b) $3.8 \mathrm{~mm}$ and (c) $6.0 \mathrm{~mm}$ 


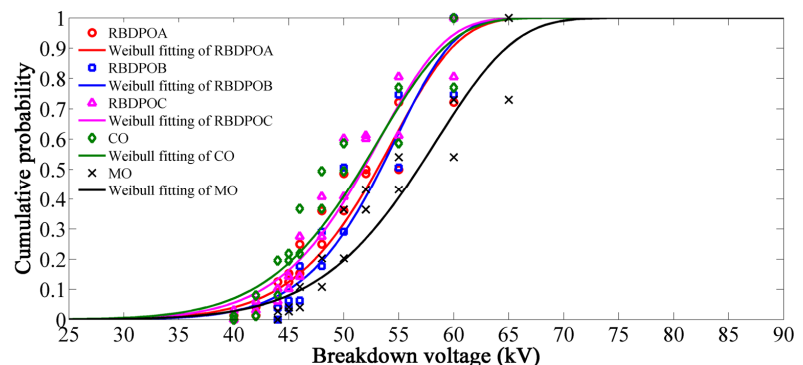

(a)

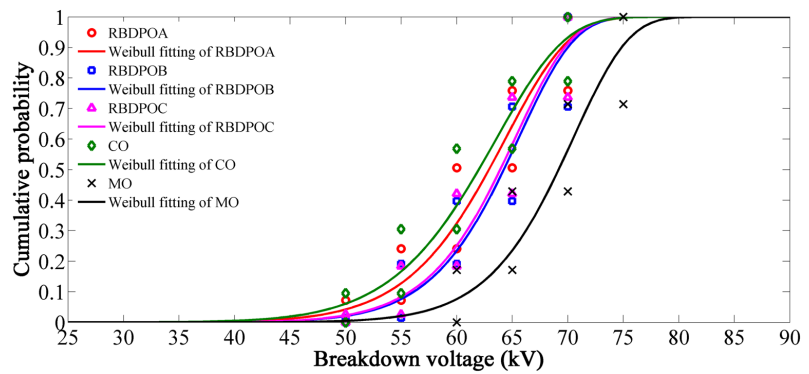

(b)

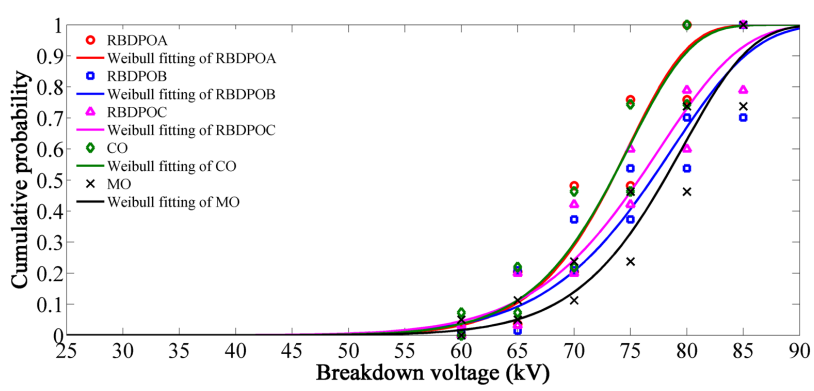

(c)

Fig. 5. Weibull cumulative probability fittings for positive polarity of all samples at gap distances of (a) $2.0 \mathrm{~mm}$; (b) $3.8 \mathrm{~mm}$ and (c) $6.0 \mathrm{~mm}$

parameters, the breakdown voltages at $1 \%$ and $50 \%$ probabilities were obtained.

Under negative polarity, the difference on the breakdown voltages among the RBPDO samples at $1 \%$ and $50 \%$ probabilities are quite small where the highest percentages of differences are only $4 \%$ and $6 \%$ at all gap distances as shown in Table 2. The breakdown voltages of $\mathrm{CO}$ are slightly lower than RBDPO where the highest percentages of differences on the breakdown voltages at $1 \%$ and $50 \%$ probabilities are $10 \%$ and $6 \%$. On the other hand, the breakdown voltages of RBDPO and $\mathrm{CO}$ are much lower than MO where the highest percentages of differences on the breakdown voltages at $1 \%$ and $50 \%$ probabilities are $17 \%$ and $13 \%$ respectively.

Under positive polarity, the highest percentages of differences on the breakdown voltages at $1 \%$ and $50 \%$ probabilities among the RBDPO samples at all gap distances are slightly higher than under negative polarity where it is between $7 \%$ and $6 \%$. The performance of $\mathrm{CO}$ is same as under negative polarity where the breakdown voltages are slightly lower than RBDPO. The difference
Table 2. Negative lightning breakdown voltages of all samples at gap distances of $2.0 \mathrm{~mm}, 3.8 \mathrm{~mm}$ and $6.0 \mathrm{~mm}$

\begin{tabular}{c|c|c|c|c}
\hline \multirow{2}{*}{ Samples } & \multirow{2}{*}{$\begin{array}{c}\text { Breakdown } \\
\text { probabilities }\end{array}$} & \multicolumn{3}{|c}{ Breakdown voltages at gap distances $(\mathrm{kV})$} \\
\cline { 2 - 5 } & $1 \%$ & $3.0 \mathrm{~mm}$ & $3.8 \mathrm{~mm}$ & $6.0 \mathrm{~mm}$ \\
\hline \multirow{2}{*}{ RBDPOA } & $1 \% .8$ & 44.8 & 49.2 \\
\cline { 2 - 5 } & $50 \%$ & 49.6 & 57.9 & 67.8 \\
\hline \multirow{2}{*}{ RBDPOB } & $1 \%$ & 34.8 & 45.0 & 51.3 \\
\cline { 2 - 5 } & $50 \%$ & 49.2 & 60.2 & 68.5 \\
\hline \multirow{2}{*}{ RBDPOC } & $1 \%$ & 37.3 & 43.0 & 49.9 \\
\cline { 2 - 5 } & $50 \%$ & 46.8 & 59.1 & 68.0 \\
\hline \multirow{2}{*}{$\mathrm{CO}$} & $1 \%$ & 34.2 & 40.6 & 49.0 \\
\cline { 2 - 5 } & $50 \%$ & 46.4 & 57.1 & 67.6 \\
\hline \multirow{2}{*}{$\mathrm{MO}$} & $1 \%$ & 37.4 & 49.0 & 56.8 \\
\cline { 2 - 5 } & $50 \%$ & 53.4 & 64.9 & 77.4 \\
\hline
\end{tabular}

Table 3. Positive lightning breakdown voltages of all samples at gap distances of $2.0 \mathrm{~mm}, 3.8 \mathrm{~mm}$ and $6.0 \mathrm{~mm}$

\begin{tabular}{c|c|c|c|c}
\hline \multirow{2}{*}{ Samples } & \multirow{2}{*}{$\begin{array}{c}\text { Breakdown } \\
\text { probabilities }\end{array}$} & \multicolumn{3}{|c}{$\begin{array}{c}\text { Breakdown voltages at gap distances } \\
(\mathrm{kV})\end{array}$} \\
\cline { 3 - 5 } & & $2.0 \mathrm{~mm}$ & $3.8 \mathrm{~mm}$ & $6.0 \mathrm{~mm}$ \\
\hline \multirow{2}{*}{ RBDPOA } & $1 \%$ & 34.8 & 44.3 & 55.4 \\
\cline { 2 - 5 } & $50 \%$ & 53.0 & 62.9 & 73.4 \\
\hline \multirow{2}{*}{ RBDPOB } & $1 \%$ & 35.4 & 47.5 & 53.6 \\
\cline { 2 - 5 } & $50 \%$ & 53.3 & 64.2 & 76.9 \\
\hline \multirow{2}{*}{ RBDPOC } & $1 \%$ & 33.4 & 47.1 & 53.6 \\
\cline { 2 - 5 } & $50 \%$ & 51.8 & 63.9 & 75.7 \\
\hline \multirow{2}{*}{$\mathrm{CO}$} & $1 \%$ & 32.0 & 42.4 & 52.8 \\
\cline { 2 - 5 } & $50 \%$ & 51.6 & 62.0 & 73.3 \\
\hline \multirow{2}{*}{$\mathrm{MO}$} & $1 \%$ & 35.7 & 52.4 & 57.8 \\
\cline { 2 - 5 } & $50 \%$ & 56.8 & 69.2 & 78.0 \\
\hline
\end{tabular}

on the breakdown voltages at $1 \%$ probability between $\mathrm{RBDPO} / \mathrm{CO}$ and MO under positive polarity is much larger than under negative polarity where the highest percentage of difference is $19 \%$. On the other hand, the highest percentage of difference on the breakdown voltages at $50 \%$ probability between $\mathrm{RBDPO} / \mathrm{CO}$ and $\mathrm{MO}$ is only $9 \%$ as shown in Table 3 . For both polarities, RBDPOB has the closest breakdown voltages with $\mathrm{MO}$ where the highest percentage of difference is less than $12 \%$.

\section{Conclusion}

There is no significant effect of voltage polarities on the $50 \%$ breakdown voltages of RBDPO and $\mathrm{CO}$ where the highest percentage of difference between negative and positive polarities at all gap distances is less than $10 \%$. On the other hand, the effect of the testing methods on the $50 \%$ breakdown voltage of RBDPO and $\mathrm{CO}$ is quite small where the highest percentage of difference is also less than $14 \%$. The lightning breakdown performances of RBDPO and $\mathrm{CO}$ are comparable with $\mathrm{MO}$ under positive polarity where the highest percentage of difference on the $50 \%$ breakdown voltages is less than $11 \%$. While under negative polarity, the $50 \%$ breakdown voltages of RBDPO and CO 
are much lower than MO with the highest percentage of difference can be up to $22.5 \%$. Further analysis based on Weibull distribution reveals that there is a small difference on the breakdown voltage at $1 \%$ probability between $\mathrm{RBDPO} / \mathrm{CO}$ and $\mathrm{MO}$ where at all gap distances the highest percentage of difference are $17 \%$ and $19 \%$ under negative and positive polarities respectively. With further studies on other aspects, RBDPO/CO could serve as an alternative for $\mathrm{MO}$ as dielectric insulating fluid in transformers.

\section{Acknowledgements}

The authors would like to thank Ministry of Education and Universiti Putra Malaysia for the funding under FRGS scheme (03-02-13-1280FR), (03-02-13-1279FR), PUTRA IPM and IPB schemes (GP-IPM/2013/9401500), (GP-IPB/ 2014/9440801). Special thanks to Hyrax Oil Sdn. Bhd and Malaysia Transformer Manufacturing Sdn. Bhd. for the technical support.

\section{References}

[1] "Sime Darby Plantation-Palm oil facts and figures," 2014.

[2] U. U. Abdullahi, S. M. Bashi, R. Yunus, Mohibullah, and H. A. Nurdin, "The potentials of palm oil as a dielectric fluid," National Proceedings of Power and Energy Conference (PECon), pp. 224-228, 2004.

[3] Suwarno and S. Aditama, "Dielectric properties of palm oils as liquid insulating materials: effects of fat content," International Symposium on Electrical Insulating Materials (ISEIM), vol. 1, pp. 91-94, June 2005.

[4] A. Rajab, Suwarno, and S. Aminuddin, "Properties of RBDPO Oleum as a candidate of palm basedtransformer insulating liquid," International Conference on Electrical Engineering and Informatics (ICEEI), vol. 02, pp. 548-552, August 2009.

[5] A. Rajab, A. S. S. Sudirham, and Suwarno, "A Comparison of dielectric properties of palm oil with mineral and synthetic types insulating liquid under temperature variation," Inst. Technology Bandung J. Eng. Sci., vol. 43, pp. 191-208, 2011.

[6] Suwarno, F. Sitinjak, I. Suhariadi, and L. Imsak, "Study on the characteristics of palm oil and it's derivatives as liquid insulating materials," International Conference on Properties and Applications of Dielectric Materials (ICPADM), vol. 2, pp. 495498, June 2003.

[7] Norhafiz Azis, Jasronita Jasni, Mohd Zainal Abidin Ab Kadir, and M. N. Mohtar, "Suitability of Palm Based Oil as Dielectric Insulating Fluid in Transformers," Journal of Electrical Engineering \& Technology, vol. 1, pp. 742-749, 2013.
[8] S. S. Sinan, S. N. Shawaludin, J. Jasni, N. Azis, M. Z. A. A. Kadir, and M. N. Mohtar, "Investigation on the AC breakdown voltage of RBDPO Olein," in IEEE Innovative Smart Grid Technologies - Asia (ISGT Asia), pp. 760-763, 2014.

[9] N. I. A. Katim, M. T. Ishak, A. M. Ishak, Y. V. Thein, N. Azis, M. Z. A. A. Kadir, et al., "Examination on the lightning breakdown strength of biodegradable oil under quasi-uniform field," IEEE International Conference on Power and Energy (PECon), pp. 17-20, 2014.

[10] Y. V. Thien, N. Azis, J. Jasni, M. Z. A. Ab Kadir, R. Yunus, M. T. Ishak, et al., "Investigation on the lightning breakdown voltage of Palm Oil and Coconut Oil under non-uniform field," IEEE International Conference on Power and Energy (PECon), pp. 1-4, 2014.

[11] D.C. Abeysundara, C. Weerakoon, J R Lucas, and K. A. I. G. a. K. C. Obadage, "Coconut oil as an alternative to transformer oil," ERU Symposium, November, 2001.

[12] B. S. H. M. S. Y. Matharage, M. A. R. M. Fernando, E. Tuncer, M. A. A. P. Bandara, and C. S. Kalpage, "Coconut oil as transformer liquid insulation - ageing and simulated thermal and electrical faults," IEEE Transactions on Dielectric and Electrical Insulation, vol. 3, pp. 887-898, 2013.

[13] J. R. Lucas, D C Abeysundara, C. Weerakoon, K B M I Perera, K C Obadage, and K. A. I. Gunatunga, "Coconut oil insulated distribution transformer," 8 th Annual Conference of the IEEE Sri Lanka, 2001.

[14] S. Ranawana, C.M.B. Ekanayaka, N.A.S.A. Kurera, M.A.R.M. Fernando, and K. A. R. Perera, "Analysis of insulation characteristics of coconut oil as an alternative to the liquid insulation of power transformers," IEEE International Conference In-dustrial and Information Systems (ICIIS), pp. 1-5, 2008.

[15] K. J. Rapp, J. Corkran, C. P. McShane, and T. A. Prevost, "Lightning impulse testing of natural ester fluid gaps and insulation interfaces," IEEE Transactions on Dielectrics and Electrical Insulation, vol. 16, pp. 1595-1603, 2009.

[16] Z. D. Wang, Q. Liu, X. Wang, P. Jarman, and G. Wilson, "Discussion on possible additions to IEC 60897 and IEC 61294 for insulating liquid tests," IET Electric Power Applications, vol. 5, pp. 486-493, 2011.

[17] L. Rongsheng, C. Tornkvist, V. Chandramouli, O. Girlanda, and L. A. Pettersson, "Ester fluids as alternative for mineral oil: The difference in streamer velocity and LI breakdown voltage," IEEE Conference on Electrical Insulation and Dielectric Phenomena, CEIDP, 2009.

[18] R. Liu, C. Tornkvist, V. Chandramouli, O. Girlanda, and L. A. A. Pettersson, "Geometry impact on streamer propagation in transformer insulation liquids," in Annual Report Conference on Electrical Insulation 
and Dielectric Phenomena (CEIDP), pp. 1-4, 2010.

[19] Q. Liu and Z. D. Wang, "Streamer characteristic and breakdown in synthetic and natural ester transformer liquids under standard lightning impulse voltage", IEEE Transactions on Dielectrics and Electrical Insulation, vol. 18, pp. 285-294, 2011.

[20] P. Rozga, M. Stanek, and D. Cieslinski, "Comparison of properties of electrical discharges developing in natural and synthetic ester at inception voltage", IEEE Conference on Electrical Insulation and Dielectric Phenomena (CEIDP), 2013.

[21] D. Vukovic, S. Tenbohlen, J. Harthun, C. Perrier, and H. Fink, "Breakdown strength of vegetable-based oils under AC and lightning impulse voltages," IEEE International Conference on Dielectric Liquids (ICDL), 2011.

[22] O. Lesaint and G. Massala, "Positive streamer propagation in large oil gaps: experimental characterization of propagation modes," IEEE Transactions on Dielectrics and Electrical Insulation, vol. 5, pp. 360370, 1998.

[23] C. T. Duy, O. Lesaint, A. Denat, N. Bonifaci, and Y. Bertrand, "Streamer propagation and breakdown in rape-seed oil at high voltage," in IEEE International Conference on Dielectric Liquids, ICDL, pp. 1-4, 2008.

[24] C. T. Duy, O. Lesaint, A. Denat, and N. Bonifaci, "Streamer propagation and breakdown in natural ester at high voltage," IEEE Transactions on Dielectrics and Electrical Insulation, vol. 16, pp. 15821594, 2009.

[25] Q. Liu and Z. D. Wang, "Breakdown and withstand strengths of ester transformer liquids in a quasiuniform field under impulse voltages," IEEE Transactions on Dielectrics and Electrical Insulation, vol. 20, pp. 571-579, 2013.

[26] Z. Zhaotao, L. Jian, Z. Pin, and S. Grzybowski, "Electrical properties of nano-modified insulating vegetable oil," Annual Report Conference on Electrical Insulation and Dielectric Phenomena (CEIDP), 2010.

[27] Q. Liu, Z. D. Wang, and F. Perrot, "Impulse breakdown voltages of ester-based transformer oils determined by using different test methods," IEEE Conference on Electrical Insulation and Dielectric Phenomena (CEIDP), 2009.

[28] R. Bartnikas, "Engineering Dielectrics-Electrical Insulating Liquids," vol. III. Varennes, Canada: ASTM 1916 Race Street Philadelphia, 1994.

[29] V.Y. Ushakov, V.F. Klimkin, and S. M. Korobeynikov, "Impulse Breakdown of Liquids," India: Springer, 2007.

[30] IEC 60897, "Methods for the determination of the lightning impulse breakdown voltage of insulating liquids," International Electrotechnical Commission, 1987.

[31] Q. Liu, "Electrical Performance of Ester Liquids
Under Impulse Voltage For Application In Power Transformers," PhD Dissertation, School of Electrical and Electronic Engineering, The University of Manchester, 2011.

[32] W. Hauschild and W. Mosch, "Statistical Techniques for High-voltage Engineering," Bristol, England: J.W.Arrowsmith Ltd., 1992.

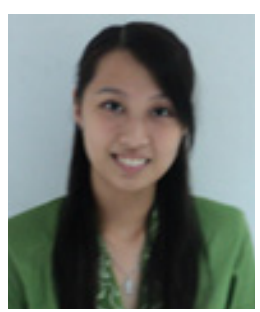

Yee Von Thien received B. Eng degree in Electrical and Electronic Engineering (Power) (2013) from Universiti Tun Hussein Onn Malaysia. Currently she is studying for her M. Sc. Degree in Master of Science in the Department of Electrical and Electronic Engineering, University of Putra Malaysia.

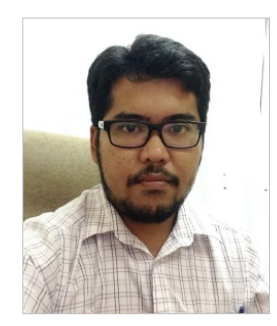

Norhafiz Azis received B. Eng degree in Electrical and Electronic Engineering (2007) from Universiti Putra Malaysia and $\mathrm{PhD}$ degree in Electrical Power Engineering (2012) from The University of Manchester in UK. Currently he is a Senior Lecturer at the Department of Electrical and Electronic Engineering, Universiti Putra Malaysia, Malaysia. His research interests are in-service ageing of transformer insulation, condition monitoring, asset management and alternative insulation materials for transformers.

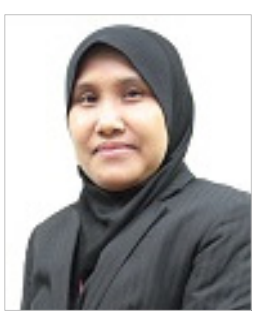

Jasronita Jasni received B. Eng degree in Electrical Engineering (1998) and M. Eng. in Electrical Engineering (2001) from Universiti Teknologi Malaysia. She received the $\mathrm{PhD}$ degree in Electrical Power Engineering from Universiti Putra Malaysia in 2010. Currently she is a Senior Lecturer in the Department of Electrical and Electronic Engineering, Universiti Putra Malaysia, Malaysia. She is an IEEE member. Her research interests include power system analysis for static and dynamics, load flow analysis, embedded generation and renewable energy.

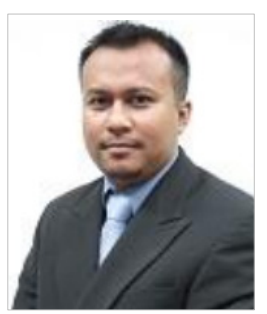

Mohd Zainal Abidin Ab Kadir received the B. Eng degree in Electrical and Electronic Engineering from Universiti Putra Malaysia in 2000 and $\mathrm{PhD}$ degree in High Voltage Engineering (2006) from The Universiti of Manchester in UK. Currently, he is a 
Professor in the Department of Electrical and Electronics Engineering, Faculty of Engineering, University Putra Malaysia. His research interests include high voltage engineering, insulation coordination, lightning protection, EMC/EMI, kerauna-medicine and power system transients.

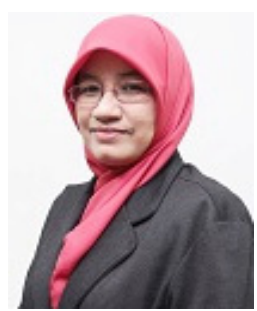

Robiah Yunus received the B. Eng degree in Chemical Engineering (1986) from University Alabama in USA and M. Eng. in Integrated Design of Chemical Plant (1989) from University of Leeds, UK. She received the PhD degree in Chemical Engineering from Universiti Putra Malaysia in 2003. Currently she is a Professor in the Department of Chemical Engineering, Universiti Putra Malaysia. Her research interests are renewable energy, reaction engineering and process engineering.

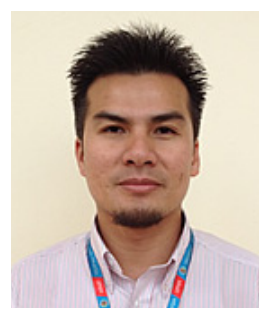

Mohd Taufiq Ishak received the B. Eng degree in Electrical Engineering (2002) from Universiti Tenaga Nasional in Malaysia and M. Eng. in Electrical Engineering (2004) from UMIST, UK. He received the PhD degree in Electrical Power Engineering from University of Manchester, UK in 2010. Currently he is a Senior Lecturer in the Department of Electrical and Electronic Engineering, Universiti Pertahanan Nasional Malaysia. His research interests are high voltage, power transformer, asset management, lifetime prediction, renewable energy, conditioning monitoring and smart grid.

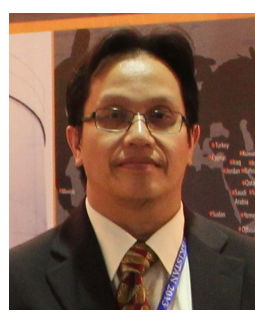

Zaini Yaakub received the degree of Applied Chemistry with Honours from Sheffield Hallam University, United Kingdom in 1993. He joined Caleb Brett Malaysia in the same year as a chemist before joining Hyrax Oil in 1994. Currently, he is an Assistant General Manager at Hyrax Oil after having had a working experience for more than 20 years on various responsibilities and roles. His research interests are in the field of electrical insulating oils and currently doing his Ph.D degree at UPM. 